This is a peer-reviewed, accepted author manuscript of the following research article: Hammad, W., Samier, E. A., \& Mohammed, A. (2020). Mapping the field of educational leadership and management in the Arabian Gulf region: a systematic review of Arabic research literature. Educational Management Administration and Leadership, 1-20. https://doi.org/10.1177/1741143220937308

\title{
Mapping the field of educational leadership and management in the Arabian Gulf region: a systematic review of Arabic research literature
}

\section{Introduction}

Despite the dramatic developments that educational leadership and management (EDLM) has witnessed over the past few decades, one of the serious limitations of the field has been the domination of Anglo-American perspectives (Blunt and Jones, 1997; Bridges, 1982). A recent review of the global EDLM knowledge base revealed that about $50 \%$ of the articles published between 2007 and 2016 came from five Anglo-Saxon countries, while the remaining 50\% came from the rest of the world (Tian and Huber, 2019a). Recognition of such a limitation has been evident in concerns raised by EDLM scholars about the universality of Western leadership theories and practices and their applicability to non-Western contexts (Bajunid, 1996; Belchetz and Leithwood, 2007; Cheng, 1995; Hallinger, 1995). This has given rise to many calling for a diversification of the existing EDLM knowledge base through increasing research efforts aimed at understanding how leadership is conceived and enacted in different cultures (Bush, 2002; Day and Leithwood, 2007; Dimmock and Walker, 1998, 2005: Oplatka and Arar, 2017). This call was clearly expressed by Dimmock and Walker (1998) who argued that research in the field needs to 'stretch beyond its current near-exclusive grounding in Western theory and move toward including more diverse perspectives from multiple cultural contexts within which educational administration takes place' (p. 559). In addition, a postcolonial literature has been growing over the past few decades, placing more emphasis on the inclusion of research coming from non-Western contexts (e.g., Saffari, Abdolmaleki and Akhbari, 2017). As a result, recent years have witnessed a dramatic increase in the volume of EDLM research from developing countries. Evidence for this growing scholarship can be found in recent reviews of EDLM research in Asia (e.g., Hallinger and Bryant 2013; Hallinger and Chen 2015; Szeto, Lee and Hallinger, 2015), Africa (Asuga, Scevak and Eacott, 2016; Bush and Glover, 2016; Gumus, Bellibas, Gumus and Hallinger, 2019; Hallinger, 2018a), Latin America (Castillo and Hallinger, 2017; Flessa, Bramwell, Fernandez and Weinstein, 2018) and the Arab region (Atari and Outum, 2019; Hallinger and Hammad, 2019; Hammad and Hallinger, 2017; Karami-Akkari and El Sahib, 2019; Oplatka and Arar, 2017). 
This is a peer-reviewed, accepted author manuscript of the following research article: Hammad, W., Samier, E. A., \& Mohammed, A. (2020). Mapping the field of educational leadership and management in the Arabian Gulf region: a systematic review of Arabic research literature. Educational Management Administration and Leadership, 1-20. https://doi.org/10.1177/1741143220937308

\section{Purpose and Objectives}

It is in the context of the current global efforts to develop the knowledge base on EDLM that this review was conducted. It seeks to examine national-language contributions to the field, that is, in this case Arabic EDLM scholarship from a particular geographic area that is largely underresearched - the Arabian Gulf states - and a region that is not as research productive as many other parts of the world (El-Baz, 2009). The purpose is to enrich the existing knowledge base by including this largely unexplored literature in English language research for the wider international community of EDLM scholars and practitioners. In doing so, the current review responds to postcolonial critiques of the domination of Western and English language scholarship (e.g., Andreotti, 2011). It specifically responds to recommendations made in previous reviews to expand the study of existing EDLM literature to include other sources such as articles published in national language journals (Atari and Outum, 2019; Hallinger and Bryant, 2013; Hammad and Hallinger). Hallinger and Bryant (2013) consider this "a high priority objective", reasoning that focusing only on literature published in international journals may not provide a full picture of the regional literature under investigation. This may explain the growing trend among EDLM scholars to include national language publications in their reviews (Hallinger, 2019). Efforts undertaken to explore national language EDLM literature in China (Walker, Hu, and Qian 2012), Turkey (Balc1 and Apaydın, 2009), and Vietnam (Hallinger, Walker, and Trung, 2015) are examples of such reviews.

Understanding how Arab educators and practitioners conceptualise leadership is of paramount importance given the significant educational developments taking place in the region and the lack of EDLM research that can inform these developments (Hallinger and Hammad, 2019; Hammad and Hallinger, 2017; Sellami, Sawalhi, Romanowsky and Amatullah, 2019). Moreover, sketching a broader picture of EDLM knowledge production in the Arab region warrants reviews of the literature published in the Arabic language since most experience and work is still conducted in Arabic. This becomes even clearer when one considers the volume of the Arab-related EDLM literature published internationally; a recent review of knowledge production on EDLM in the Arab region identified only 62 research articles published in nine core EDLM journals between 
This is a peer-reviewed, accepted author manuscript of the following research article: Hammad, W., Samier, E. A., \& Mohammed, A. (2020). Mapping the field of educational leadership and management in the Arabian Gulf region: a systematic review of Arabic research literature. Educational Management Administration and Leadership, 1-20. https://doi.org/10.1177/1741143220937308

2000 and 2016 (Hallinger and Hammad, 2019). This is indeed a small number when compared with the total number of articles (more than 4000) published in these journals over the same period of time. Added to this is a lack of literature review studies published internationally on Arabic language sources (see Atari and Outum, 2019). This not only indicates how little is known internationally about EDLM in the Middle East, but also confirms the need for representing local scholarship across Arab societies in order to gain a deeper understanding of EDLM practices and challenges in the region.

The review was guided by the following research questions:

1) What is the geographical distribution of the Gulf EDLM Arabic research literature published between 2009 and 2018 across the GCC member states?

2) What authorship trends characterise this literature in terms of collaboration (singleauthored, co-authored), author gender, and author affiliation (academic, practitioner)?

3) What is the nature of this literature in terms of study type (empirical, conceptual/commentary, research review)?

4) What research topics were studied by EDLM scholars in the Gulf States?

5) What research methods were preferred by scholars studying EDLM in the Gulf states?

This review is limited to EDLM literature related to the Arabian Gulf states. The term 'Gulf states' refers to the six monarchies comprising the Gulf Cooperation Council (GCC), namely Bahrain, Kuwait, Oman, Qatar, Saudi Arabia, and the United Arab Emirates (UAE). They were chosen as a unit for this study because although they share many cultural, social, political and organisational features with the rest of the Arab world, the Gulf states have a number of specific characteristics that make them a unique context for the study of EDLM (Bailey, Purinton, AlMahdi and Al Khalifa, 2019). Clearly, there are differences among these monarchies in terms of constitutions, types of shari'ah used, culture, and socio-economic and political institutions (see Miller, 2016; Wiseman, Alromi and Alshumrani, 2014; Zahlan, 2017) that influence the educational systems they have and the types of educational administration and leadership exercised (e.g., Sunal and Mutua, 2013). For example, the UN Human Development reports on indices and indicators for the Gulf region (2018) and the Oxford Gulf \& Arabian Peninsula Studies Forum 
This is a peer-reviewed, accepted author manuscript of the following research article: Hammad, W., Samier, E. A., \& Mohammed, A. (2020). Mapping the field of educational leadership and management in the Arabian Gulf region: a systematic review of Arabic research literature. Educational Management Administration and Leadership, 1-20. https://doi.org/10.1177/1741143220937308 report (2017) demonstrate how differing policies and programmes have led to much larger numbers of UAE students studying abroad than Bahraini. However, there are also commonalities that distinguish these societies from other Arab countries, such as their shared security problems, shared waterways for trade, in addition to shared cultural practices that are not common to the rest of the Middle East (Al-Yousef, 2017). Economically, unlike other Arab countries which lacked the financial resources needed to meet their ambitious development plans upon achieving independence, the Gulf states had already accumulated substantial wealth from oil revenues. Surpluses of petrodollars enabled these countries to invest in improving their social services including education (Bahgat, 1999), establishing many higher education organisations and the infrastructure for teaching, research and international networking (Ally and Alshahrani, 2018). However, it is important to consider that the Gulf region is composed mostly of very new states that are still undergoing nation-building and the construction of higher education and research capacity with more emphasis on knowledge distribution than knowledge creation. Universities in many Gulf countries have high faculty turnover, and tend to have difficulty attracting and retaining high research performance scholars, necessary to building a strong research culture. This is particularly true for the social sciences where intellectual capital and an institutional culture that understands and is willing to participate as subjects of research are more crucial factors than large material resources and technology (Ryan and Daly, 2018). These factors need to be considered when evaluating EDLM knowledge production in the region.

The developments taking place in GCC countries have encouraged researchers to consider the role of educational leadership and the importance of modifying borrowed leadership theories to local cultures in the region (Bailey et al., 2019; Sellami et al., 2019). For example, based on their insider's experience in Bahrain, Bailey and colleagues (2019), similar to many scholars in postcolonial and policy transfer literatures in primary disciplines like political science, sociology, psychology and cultural studies (e.g., Kitayama \& Cohen, 2007; Rodriguez, Boatcă and Costa, 2010), have emphasised the need to conceptualise EDLM in the GCC countries in order to provide culturally-appropriate frameworks needed for the ongoing educational reforms in the region, arguing that imported, mainly Western, approaches to educational leadership are limited "in speaking to practitioners from GCC cultures" (p. 2). As they suggest, this might explain the many 
This is a peer-reviewed, accepted author manuscript of the following research article: Hammad, W., Samier, E. A., \& Mohammed, A. (2020). Mapping the field of educational leadership and management in the Arabian Gulf region: a systematic review of Arabic research literature. Educational Management Administration and Leadership, 1-20. https://doi.org/10.1177/1741143220937308 challenges facing GCC countries in their attempts to adapt Western leadership theories to their local contexts.

\section{Methodology}

Since the aim of the study is to analyse patterns of EDLM knowledge production in the Gulf region through mapping the salient features characterising this body of literature rather than an investigation of the nature of these features, a structural/functional rather than an interpretive/critical (Bryman, 2016) approach was adopted. The study used quantitative methods based on descriptive statistics to highlight modal trends describing the literature under review. The method adopted here is the systematic review, well established in the social sciences (Pettigrew and Roberts, 2006), including the selection of a research topic and scope, establishment of inclusion and exclusion criteria, and selection of the databases (Zawacki-Richter et al. 2020). Similar methods were used in previous EDLM research reviews (e.g., Atari and Outum, 2019; Bellibaş and Gümüş, 2019; Castillo and Hallinger, 2017; Hallinger and Bryant 2013; Hallinger, 2018a; Hallinger and Hammad, 2019;).

Different search strategies have been used by previous EDLM research reviews to identify relevant sources. Some employed unbounded search methods which involve the use of search engines such as Googlescholar to identify EDLM sources published in the English language (e.g., Hallinger, 2018a). Others identified potential sources by scanning a delimited set of international EDLM journals available online (e.g., Bellibaş and Gümüş, 2019; Castillo and Hallinger, 2017; Hallinger and Chen 2015; Hallinger and Hammad, 2019; Hammad and Hallinger, 2017). For the purpose of conducting a review of an Arabic-language literature, it was deemed unsuitable to use Googlescholar as a search tool for reasons to do with accessibility. In addition, focusing on a specific set of Arabic language educational journals may only produce a limited number of sources

since not all Arabic journals have been fully digitised. Further, with the exception of only one journal published by the Egyptian Society for Comparative Education and Educational Administration, there are no Arabic language journals specialised in publishing EDLM research. Most Arabic educational journals are published by higher education institutions and all have a cross-disciplinary orientation (Atari and Outum, 2019). Therefore, an open search technique was adopted by using Arabic databases available online to find relevant sources. The search began with 
This is a peer-reviewed, accepted author manuscript of the following research article: Hammad, W., Samier, E. A., \& Mohammed, A. (2020). Mapping the field of educational leadership and management in the Arabian Gulf region: a systematic review of Arabic research literature. Educational Management Administration and Leadership, 1-20. https://doi.org/10.1177/1741143220937308

Dar Almandumah since it is more reliable and comprehensive because it hosts a number of Arabic databases specialised in social sciences and humanities such as EduSearch, EcoLink, IslamicInfo, AraBase, and Humanindex. One feature of this search engine is that it enables users to search within all these databases at the same time. However, the vast majority of relevant sources were found in the EduSearch database as it is mainly specialised in education in constrast to the other databases. The searched databases contained a wide range of sources including journal articles, dissertations and conference proceedings. The search was limited to research articles with parameters set for identification of relevant sources including: 1) articles focusing on EDLM in K12 schools and/or tertiary education; 2) articles from/about Arabian Gulf states; 3) articles published between 2009 and 2018; and 4) articles available in full text format. A set of Arabic search terms were used to find potential articles. These included terms translated as 'educational leadership/administration', 'school leadership/administration', 'principal, 'school leader', 'head of department', 'senior teacher', 'instructional supervision/supervisors','organisational', 'decisionmaking', and 'empowerment'. Additionally, the Shamaa database was examined to locate more possible sources using the same keywords and criteria. Only a few more articles were found that were not available in Dar Almandumah. In their review of the Arabic EDLM literature documented in the Shamaa database, Karami-Akkari and El-Saheb (2019) found that $77.7 \%$ of the articles were from Arab countries outside the Gulf region.

The initial search within these databases yielded more than 400 EDLM articles related to Gulf countries. An additional set of criteria for inclusion in the review were applied to filter the dataset to ensure a consistent degree of academic quality. These included: 1) articles published in journals affiliated with universities or educational research institutions/associations; 2) articles that have a clear focus on EDLM; 3) articles that are not excerpts from research students' dissertations, and 4) articles that have clear/detailed research methods. Upon application of these criteria, a number of articles were excluded from the review, thus bringing the final number of sources down to 272. Although it is beyond the scope of the current review, it is worth noting that almost half of these articles (48\%) were published in Egyptian journals, while most of the remaining articles were published in GCC journals, especially from Saudi Arabia, Kuwait, Bahrain and Oman, respectively. Only 15 articles were published in Jordanian journals. 
This is a peer-reviewed, accepted author manuscript of the following research article: Hammad, W., Samier, E. A., \& Mohammed, A. (2020). Mapping the field of educational leadership and management in the Arabian Gulf region: a systematic review of Arabic research literature. Educational Management Administration and Leadership, 1-20. https://doi.org/10.1177/1741143220937308

Articles were scanned to extract data relevant to the research questions. These included article titles, year of publication, country name, types of articles, school level, research topics, research methods, data collection techniques, and levels of statistical analysis. Extracted data were entered into an MS Excel spreadsheet and codes were used to facilitate quantitative analysis. For example, article types were coded as follows: empirical paper $=1$, conceptual paper $=2$, commentary $=3$, research review $=4$. Similarly, research topics were coded (e.g., Leadership $=8$, Principals $=9$, Gender $=12$, etc. $)$. It is important to note that the majority of articles $(78 \%)$ were categorised according to multiple topics. For example, studies on principal leadership styles were coded 8 for 'Leadership' and 9 for 'Principals'.

Measures to ensure reliability were observed at the different stages of this review, from identification of potential sources to data extraction and coding. Specifically, interrater reliability is an important issue to consider when conducting systematic reviews involving multiple researchers (Belur, Tompson, Thornton and Simon, 2018). The current review used predetermined, clearly-defined inclusion/exclusion criteria for the screening of relevant literature. Further, the criteria used for categorising the studies were straightforward classifications that did not require interpretations (i.e. study types, author gender/affiliation, school level, research topics, and methods), thus ensuring a high level of agreement among the coders since differences in rating were very rare.

Data were analysed quantitatively using graphs and tables to illuminate salient patterns of knowledge production. Trends identified in the database were benchmarked against those found in previous reviews of Arab-related EDLM research published internationally (Hallinger and Hammad, 2019; Hammad and Hallinger, 2017; Oplatka and Arar, 2017), and locally (Atari and Outum, 2019; Karami-Akkari and El-Saheb, 2019), as well as reviews of EDLM research from other developing societies (e.g., Bellibaş and Gümüş, 2019; Castillo and Hallinger, 2017; Hallinger and Chen 2015; Hallinger, 2018a).

\section{Results}

Drawing upon a dataset of 272 Gulf-related EDLM research articles documented in Dar Almandumah and Shamaa, this section presents the findings with regards to EDLM research geographic distribution, types of studies, research topics, as well as methods employed in the 
This is a peer-reviewed, accepted author manuscript of the following research article: Hammad, W., Samier, E. A., \& Mohammed, A. (2020). Mapping the field of educational leadership and management in the Arabian Gulf region: a systematic review of Arabic research literature. Educational Management Administration and Leadership, 1-20. https://doi.org/10.1177/1741143220937308 articles. As discussed above, the focus in this review was on highlighting patterns of knowledge production rather than synthesising research findings.

\section{Insert figure 1 here}

\section{Geographic distribution of the Gulf EDLM literature}

The first analysis concerned how the Gulf EDLM literature published between 2009 and 2018 was distributed across the six nations comprising the Gulf region. It is worth noting that the 272 studies included in this review are almost 11 times the size of the Gulf EDLM literature $(\mathrm{N}=26)$ published in the English language in core EDLM international journals in a 17-year period (2000-2016) (Hallinger and Hammad, 2019). This is understandable when one considers language as a considerable barrier that can hinder non-English speaking scholars from publishing their research in international journals (Gumus et al., 2019), particularly in relatively new countries where the higher education system and scholarship are still in development along with other forms of infrastructure. This pattern is also in line with findings reported in similar reviews of EDLM research from other developing societies such as Turkey (Gumus et al., 2019) and Vietnam (Hallinger, Walker and Trung, 2015).

Concerning geographic coverage, variations in the volume of EDLM research across nations have been noted in previous reviews of EDLM research from developing societies (e.g., Atari and Outum, 2019; Castillo and Hallinger, 2017; Flessa et al, 2018; Hallinger and Bryant, 2013; Hallinger and Hammad, 2019; Tian and Huber, 2019a). Consistent with these findings, the analysis found a strikingly uneven distribution of the literature: as charted in Figure 1, 62.5\% $(\mathrm{N}=170)$ of the articles were about/from Saudi Arabia, which makes this society the largest producer of EDLM knowledge in the region, reflecting the many universities that have been established and the amount of research money made available in comparison with the much smaller countries in the Gulf. Kuwait and Oman have demonstrated a relatively moderate capacity for EDLM knowledge production as they have published $20 \%$ and $12.5 \%$ of the articles, respectively. Conversely, the UAE and Bahrain have demonstrated limited capacity for EDLM research: combined together, they have published only $4.8 \%$ of the corpus under review. No

articles from Qatar were identified. However, when compared with the Gulf EDLM literature 
This is a peer-reviewed, accepted author manuscript of the following research article: Hammad, W., Samier, E. A., \& Mohammed, A. (2020). Mapping the field of educational leadership and management in the Arabian Gulf region: a systematic review of Arabic research literature. Educational Management Administration and Leadership, 1-20. https://doi.org/10.1177/1741143220937308

published internationally, a different picture emerges: although the same significant variations featured in this literature, the UAE stood out as the most active producer of EDLM research as it produced 15 out of the 26 articles related to the Gulf region (Hallinger and Hammad, 2019). This reflects the national policies requiring that most universities operate in English as well as promotion systems favouring publication in high impact international journals (Hanafi and Arvanitis (2014).

\section{Insert table 1 here}

\section{Authorship trends}

The next question concerned the authorship trends featuring in the dataset examined. The papers were first analysed according to whether they were single-authored or co-authored. As displayed in Table 2, the analysis revealed that most of the papers (69\%) were single-authored. Co-authored papers represented $31 \%$ of the corpus. In terms of author gender, it was found that most of the papers $(69 \%)$ were written by male researchers, whereas those written by female researchers represented $21 \%$ of the database. 10 per cent of the papers were joint projects involving both male and female authors. The papers were also analysed by author affiliation. It was found that 76.4 per cent of the papers were written by academics working in higher education institutions in the Gulf states, 13.6 per cent by non-academic contributors, and the remaining 10 percent were collaborative projects between academics and non-academics. Non-academic authors were found to be practitioners working in schools, ministries of education or local educational authorities in the region. A few of them were research students publishing with their supervisors.

\section{Analysis by type of study}

The following analysis focused on the composition of the Gulf EDLM database with respect to the types of studies. The articles were classified into three categories based on a typology of empirical studies, conceptual/ commentary papers, or research reviews (Creswell, 2018). Empirical studies collect and analyse quantitative and/or qualitative data to answer explicit research questions. Conceptual/theory or model building (Jaccard and Jaccoby, 2020) papers suggest or apply models aimed at understanding issues and practices related to EDLM, while commentary papers analyse 
This is a peer-reviewed, accepted author manuscript of the following research article: Hammad, W., Samier, E. A., \& Mohammed, A. (2020). Mapping the field of educational leadership and management in the Arabian Gulf region: a systematic review of Arabic research literature. Educational Management Administration and Leadership, 1-20. https://doi.org/10.1177/1741143220937308

EDLM issues or problems using a combination of personal experience and/or reference to a specific body of literature to. Research reviews aim to analyse information extracted from a clearly identified body of literature.

As Figure 2 indicates, the articles reflected a considerably imbalanced composition in terms of study types: empirical studies comprised the vast majority (92.3\%) of the Gulf-related literature. Taken together, conceptual and commentary articles represented only 7.3 per cent of the studies. The analysis identified only one research review in the corpus under investigation. When this pattern was compared with findings reported for the Arab-related EDLM literature published in international journals, a striking similarity was found between the two literatures, especially with regard to the predominance of empirical studies and the absence of research reviews (Hallinger and Hammad, 2017). Similar patterns were reported in recent reviews of EDLM scholarship from other developing countries (see Castillo and Hallinger, 2017; Gumus et al., 2019; Hallinger and Chen, 2015).

\section{Insert figure 2 here}

\section{Research topics covered in the Gulf EDLM literature}

The purpose of the next research question was to identify the topical coverage as reflected in the Gulf EDLM literature. First examined was the 'level of schooling'. As reported in Figure 3, 72.8\% of the papers $(\mathrm{N}=198)$ focused on $\mathrm{K}-12$ schools, 6.6\% $(\mathrm{N}=18)$ on higher education, and $17 \%$ $(\mathrm{N}=46)$ on education systems. It was also observed that more than half of the Gulf EDLM studies of K-12 schools $(\mathrm{N}=106)$ collected data from 'multiple levels' rather than from primary $(\mathrm{N}=11)$, middle $(\mathrm{N}=10)$ or secondary schools $(\mathrm{N}=70)$. In contrast with the Arab EDLM literature published internationally (Hammad and Hallinger, 2017), scholars studying EDLM in the Gulf region showed less interest in studying EDLM practices in higher education institutions. This is also in contrast with Atari and Outum's (2019) finding that studies on higher education administration represented 28.9 per cent of the Arabic language literature they reviewed.

\section{Insert figure 3 here}


This is a peer-reviewed, accepted author manuscript of the following research article: Hammad, W., Samier, E. A., \& Mohammed, A. (2020). Mapping the field of educational leadership and management in the Arabian Gulf region: a systematic review of Arabic research literature. Educational Management Administration and Leadership, 1-20. https://doi.org/10.1177/1741143220937308

\section{Insert table 2 here}

The next step was to classify topics in the Gulf database. For this purpose, a typology was developed drawing on previous EDLM reviews (Atari and Outum, 2019; Bellibaş and Gümüş, 2019; Hallinger and Chen, 2015; Karami-Akkari and El-Saheb, 2019). A number of topics were added and others modified to suit the Gulf literature. Data charted in Table 2 demonstrate that studies about school principals topped the list of topics with a total number of 129 articles (47.4\%). These were followed by studies exploring school management roles and practices (32\%), school leadership (29.4\%), instructional supervision and teacher evaluation (19.9\%), human resources $(15.4 \%)$, gender (13.2\%), and organisational behaviour climate and culture (12.5\%). Interestingly, three of these topics, namely principals, leadership, and organisational behaviour, climate and culture also topped the list of topics studied in the Arab EDLM literature published in international journals. However, while instructional supervision featured in the list of topics studied in the Gulf Arab-language corpus, it did not appear as a topic in the English-language literature (see Hammad and Hallinger, 2017). Moreover, when compared with EDLM literature from other developing societies, it was noted that a number of topics that were studied by scholars in these societies were either absent from the Gulf literature or only given minimal attention. These included social justice, middle-level leadership, and cultural contexts. Similar findings were reported by Atari and Outum (2019) in their review of the Arabic EDLM literature from other Arab countries, mostly Jordan. It was also observed that certain topics were specific to the Gulf EDLM dataset. For example, the subset of studies on school management roles and practices included articles that addressed issues such as managerial creativity, crisis management, time management, and electronic management. These issues did not represent a topical focus for scholars studying EDLM in other developing countries (e.g., Bellibaş and Gümüş, 2019; Castillo and Hallinger, 2017).

\section{Insert figure 4 here}

\section{Research methods employed in the Gulf EDLM literature}


This is a peer-reviewed, accepted author manuscript of the following research article: Hammad, W., Samier, E. A., \& Mohammed, A. (2020). Mapping the field of educational leadership and management in the Arabian Gulf region: a systematic review of Arabic research literature. Educational Management Administration and Leadership, 1-20. https://doi.org/10.1177/1741143220937308

Analysis of the Gulf EDLM literature with respect to types of study showed that 251 (92.3\%) of the 272 articles were empirical in nature. This subset of articles was classified according to their use of quantitative, qualitative or mixed research methods (see Figure 4). The analysis revealed that 98 per cent of the empirical articles $(\mathrm{N}=246)$ used quantitative methods, to some extent reflecting a strong American higher education globalisation influence (Romani, 2009). Both qualitative and mixed methods represented only 2 per cent $(\mathrm{N}=5)$ of the empirical subset. This clearly signals heavy reliance on quantitative research methods among scholars studying EDLM in the Gulf region. While this pattern aligns with what Atari and Outum (2019) found in their review of the Arabic-language EDLM literature from other Arab societies, it contrasts with findings reported for the Arab EDLM literature published internationally which demonstrated a balanced distribution of studies by research methods. Analysis of this literature showed that out of 26 articles related to the Gulf region, 11 articles were quantitative in nature, while 9 articles used qualitative and mixed methods (Hammad and Hallinger, 2017). Moreover, when compared with EDLM literatures from other developing societies (e.g., Bellibaş and Gümüş, 2019; Hallinger and Chen, 2015; Castillo and Hallinger, 2017), (), the Gulf EDLM literature demonstrated significantly higher preference for quantitative methods.

\section{Insert figure 5 here}

Next, the empirical articles were analysed with respect to their methods of data collection (see Figure 5). It was found that, in line with the predominance of quantitative studies, surveys were used in 98.8 per cent $(\mathrm{N}=248)$ of the empirical subset. Qualitative data collection methods were only employed in four studies. These included Interviews $(\mathrm{N}=4)$ and observation $(\mathrm{N}=1)$. None of the studies have employed document analysis for data collection. This heavy emphasis on surveys as a data collection technique bears resemblance with the early EDLM research conducted in the 1960s where the use of surveys was the norm (Briner and Campbell 1964; Bridges 1982; Campbell 1979).

The quantitative and mixed methods subset $(\mathrm{N}=248)$ was analysed from the perspective of the statistical tests employed in the studies. Previous EDLM reviews have reported the use of weak statistical analyses as a feature of underdeveloped literatures (Bridges, 1982; Hallinger and 
This is a peer-reviewed, accepted author manuscript of the following research article: Hammad, W., Samier, E. A., \& Mohammed, A. (2020). Mapping the field of educational leadership and management in the Arabian Gulf region: a systematic review of Arabic research literature. Educational Management Administration and Leadership, 1-20. https://doi.org/10.1177/1741143220937308

Chen, 2015). The same four-level rubric employed by these reviews was employed in order to classify the Gulf EDLM studies according to their statistical methods. Based on this rubric, Level 1 refers to descriptive statistics such as mean and standard deviation. Level 2 refers to correlational statistics such as t-test and Pearson's correlation. Level 3 describes correlational tests with single controls such as ANOVA. Level 4 refers to multivariate tests involving multiple factor and advanced modelling such as multiple regression, factor analysis and structural equation modelling.

\section{Insert figure 6 here}

As shown in Figure 6, it was found that 63.7 per cent of the quantitative and mixed methods articles used Level $3(\mathrm{~N}=141)$ and Level $4(\mathrm{~N}=17)$ statistical analyses, while studies using Level 1 and Level 2 analyses represented 36.3 per cent of the subset. This shows a relatively high capacity for using advanced statistics among Arab EDLM scholars. It also reflects a greater development in quantitative research methods than in qualitative and mixed methods. Similar findings were reported for the Arab EDLM literature published internationally (see Hammad and Hallinger, 2017). However, the ratio of Level 3 to Level 4 statistics was significantly different in the two literatures. While the ratio for the international literature was 9 per cent to 53 per cent, it was 56.8 per cent to 6.8 per cent in the case of the Gulf literature, thus highlighting a greater capacity among Arab EDLM scholars publishing internationally for employing multivariate statistics.

\section{Discussion}

The purpose of this review was to identify trends in EDLM knowledge production in the Arabian Gulf region. Drawing on a database of 272 EDLM studies published in local, Arabic-language journals over a ten-year period (2009-2018), the review found that the literature under investigation reflected many of the features characterising EDLM research in the Arab region at large (Atati and Outum, 2019; karami-Akkari and El-Saheb, 2019), as well as literatures from other developing countries, especially in terms of its topical coverage and selection of research methods (e.g., Bellibaş and Gümüş, 2019; Castillo and Hallinger, 2017; Hallinger and Bryant 2013; 
This is a peer-reviewed, accepted author manuscript of the following research article: Hammad, W., Samier, E. A., \& Mohammed, A. (2020). Mapping the field of educational leadership and management in the Arabian Gulf region: a systematic review of Arabic research literature. Educational Management Administration and Leadership, 1-20. https://doi.org/10.1177/1741143220937308

Hallinger, 2018a;). This section discusses the implications of the findings in the context of international literature in the field, evaluates practices in terms of their value to educational development in the region, as well as discusses some of the causes that have influenced these research practices.

The review found a strikingly uneven geographical distribution of the body of literature analysed: scholars from Saudi Arabia emerged as the most active producers of EDLM knowledge in the region as they published $62.5 \%$ of the articles reviewed. This is not surprising, given the fact that Saudi Arabia has the largest higher education system in the region and was the first GCC country to initiate postgraduate degrees in EDLM. According to Al-Jasser (2017), the first postgraduate EDLM programme in the region was established in Um Al-Qura University in 1976, ten years before any other Gulf university launched a similar initiative. What such uneven distribution signals is that very little is known about EDLM practices and challenges in other GCC societies, especially Qatar the UAE and Bahrain. Lack of Arabic EDLM research from these countries may be attributed to higher education policies, especially in UAE and Qatar, favouring English as a language of instruction and research publication as part of their nation-building and modernisation strategies (Cook, 2017) as well as their ambitious plans to be international education hubs (Ibnouf, Dou and Knight, 2014).

Uneven distribution was also noted with regard to study types; the corpus of Arabic literature was comprised mostly of empirical studies $(\mathrm{N}=251)$, with only 20 conceptual and commentary articles, and a single research review. Similar results were found by Atari and Outum (2019) in their review of Arabic EDLM literature from other Arab societies, and by Hammad and Hallinger (2017) in their review of the Arab-related literature written in the English language. This imbalanced composition suggests the need for EDLM scholars in the region to exert more effort to address this lacuna in research as it raises questions about the maturity of the Arab EDLM knowledge base (Atari and Outum, 2019; Karami-Akkari and El-Saheb, 2019).

Analysis of authorship trends revealed some interesting results. First, it was found that the majority of articles were single-authored. This differs from Atari and Outum's (2019) finding that 57.4 per cent of the Arabic articles they reviewed were co-authored. They attributed this high percentage to the fact that many of the articles were actually extracts of postgraduate students' 
This is a peer-reviewed, accepted author manuscript of the following research article: Hammad, W., Samier, E. A., \& Mohammed, A. (2020). Mapping the field of educational leadership and management in the Arabian Gulf region: a systematic review of Arabic research literature. Educational Management Administration and Leadership, 1-20. https://doi.org/10.1177/1741143220937308

dissertations published jointly by the students and their supervisors, which was not the case in the current review. However, this study's finding aligns with Hanafi and Arvanitis' (2015) observation that writing collaboratively is not a normal practice among social scientists in the Arab world. Second, EDLM scholarship in the Gulf region appeared to be male-dominated. This is evidenced by the finding that most of the articles were written by male authors. As Young and Skrla (2012) suggest, lack of women representation in EDLM research could be attributed to existing barriers to advancement standing in the way of female EDLM scholars. This is despite improvements in gender diversity in global EDLM research in the past few decades (Hallinger and Kovačević, 2019). Third, the review noted a lack of practitioners' participation in EDLM knowledge production, thus indicating academics' domination of the field. As Riehl, Larson, Short and Reitzug (2000) argue, collaboration between researchers and practitioners is crucially important for producing relevant EDLM knowledge. They also point out that lack of collaboration between both groups widens the gap between research and practice.

Two particular features of the literature under study are worth highlighting due to their relevance to developing a mature body of research literature, namely topical coverage and research methods. With regards to the topical coverage, the analysis found that topics that have gained prominence in the global EDLM literature such as the impact of cultural contexts on leadership practices, leadership for social justice, leadership for educational change, and the role of school leadership in improving students' learning have been either left untouched, or, at best, tentatively studied in this literature (see Tian and Huber, 2019b). Even when gender was studied in some articles, the focus was mostly on how both genders differed in their perceptions/practice of a particular aspect of school management/leadership. Similar gaps were identified in Oplatka and Arar's (2017) qualitative analysis of Arab EDLM studies published internationally. The review reported the absence of issues such as gender inequalities, social justice, power relations, and resistance to change from the studies. The authors attributed this to the irrelevance of such issues to the political and cultural traditions prevalent in the region. The political context in the Arab region is often characterised by unitary authority structures reflecting a socio-cultural norm of 'large power distance' (Obeidat et al., 2012). As Oplatka and Arar (2017, p. 301) suggest, this puts researchers working in these contexts under a huge pressure as they 'have to be very careful in 
This is a peer-reviewed, accepted author manuscript of the following research article: Hammad, W., Samier, E. A., \& Mohammed, A. (2020). Mapping the field of educational leadership and management in the Arabian Gulf region: a systematic review of Arabic research literature. Educational Management Administration and Leadership, 1-20. https://doi.org/10.1177/1741143220937308 publishing findings that might be seen by the authorities as provocative or incompatible with local educational policies' (p. 301).

Second, on the positive side, the current review found a few topics studied in a considerable concentration of articles. These included school principals, school management roles and practices, school leadership, and instructional supervision. This is important for knowledge accumulation needed for making progress on important issues related to policy and practice in the region (Hallinger, 2011; Leithwood, 2005). It was also intriguing to find certain topics that seemed to be specific to this corpus such as managerial creativity, crisis management, electronic management, and time management. Additionally, and in accordance with Atari and Outum's (2019) results, issues such as quality management, ICT, knowledge management, and empowerment attracted the attention of some Gulf EDLM scholars. According to the aforementioned study, these topics have become very popular in the Arab region due to growing pressures for "good governance and reform”. We agree with Karami-Akkari and El-Saheb's (2019) argument that this signals a growing recognition on the part of Arab EDLM scholars of the importance of choosing research topics that address the real concerns of their respective societies. This also corresponds with Hallinger's (2020, p.226) speculation that 'distinctive sets of topical priorities' may emerge to reflect the needs and interests of different local educational contexts.

Bridges (1982) stressed the skillful selection and application of research methods as a requirement for making intellectual progress. The review revealed limitations related to the methodological choices made by EDLM researchers in the Gulf region. Most notably, unlike internationally-published Arab EDLM literature which demonstrated some degree of balance between quantitative, qualitative and mixed research methods (see Hammad and Hallinger, 2017), the Arab-language Gulf literature showed excessive reliance on quantitative methods, with surveys being the sole data collection technique. While consistent with features reported for early EDLM research in the West (Briner and Campbell 1964; Bridges 1982; Campbell 1979), this is a negative research practice that can impede the methodological rigour needed for exploring the complexity of EDLM issues and making substantive advances in the field (Hammad and Hallinger, 2017). Moreover, despite strengths noted for using advanced statistical tests, there was little evidence of how these tests contributed to producing meaningful outcomes. For example, the majority of the correlative studies used the tests mainly to examine the significance of the differences in 
This is a peer-reviewed, accepted author manuscript of the following research article: Hammad, W., Samier, E. A., \& Mohammed, A. (2020). Mapping the field of educational leadership and management in the Arabian Gulf region: a systematic review of Arabic research literature. Educational Management Administration and Leadership, 1-20. https://doi.org/10.1177/1741143220937308

perceptions caused by demographic factors such as gender, years of experience, location, and qualification, without trying to understand how these factors actually affect the phenomenon under investigation. This caused the studies to remain on the 'descriptive level', being unable 'to identify both cause-effect relations and significant correlations between the researched topic and independent/dependent variables' (Oplatka and Arar, 2017, p. 300). This was compounded by the absence of a clear, coherent conceptual/theoretical framework that guided most of the studies. Similar findings were reported by Karami-Akkari and El-Saheb (2019) and Oplatka and Arar (2017).

One of the constraints in many developing and non-Western regions and countries like the Arabian Gulf is the domination of many fields of study under globalisation through imported curriculum, branch campuses and partnerships. This not only prescribes the curriculum and texts that are valuable, but also, if having a strong US focus tends towards quantitative research methods (Altbach, 2015; Noori and Anderson, 2013). Related to these conditions is research legitimacy often interpreted to mean using 'scientific' standards of knowledge creation. This leads to an 'overreliance' on positivistic methods producing a large percentage of quantitative studies and, what Woodside (2013 2016) calls an 'inappropriate application' of many Western theories, models and research methodologies that do not apply in their unmodified form to the social institutions in Middle East states. The research methods literature has changed over the last two decades in terms of cultural and international sensitivities (see Liamputtong, 2008; Silverman, 2017). We argue that for many fields, like educational administration and leadership, with strong social and cultural contextual dimensions and countries that are still quite traditional with social institutions reflecting long standing traditions and values, qualitative research methods are more suitable in studying lived experiences, particularly ethnography and hermeneutics that is centred on the research subject's point of view (see Creswell and Poth, 2017; Denzin and Lincoln, 2005; Glesne, 2011). The domination of positivistic and quantitative methods implies that many aspects of educational administration and leadership in the Gulf are not studied. This might explain the blank spots identified in the topical coverage of the literature under investigation.

\section{Recommendations}


This is a peer-reviewed, accepted author manuscript of the following research article: Hammad, W., Samier, E. A., \& Mohammed, A. (2020). Mapping the field of educational leadership and management in the Arabian Gulf region: a systematic review of Arabic research literature. Educational Management Administration and Leadership, 1-20. https://doi.org/10.1177/1741143220937308

In concluding this paper, the authors would like to provide some recommendations to enhance the quality of EDLM research in the Gulf region. The first recommendation concerns the topical coverage encompassed in the Gulf EDLM literature. It is recommended that scholars in the region exert more efforts to fill the 'blank spots' (Karami-Akkari and El-Saheb, 2019) found in this growing literature. They need to widen the scope of their research interests to include issues that are relevant to their local contexts but at the same time are connected with the global literature. Some possible topics include social justice, gender, leadership for change, cultural contexts' impact on leadership, as well as the effects of leadership on school outcomes, especially students' learning and teachers' professional development. Also important are issues related to modernisation, expatriates, and globalised education and the potential negative effects of foreign curricula and teaching, especially as there are tensions and challenges associated with the presence of international schools in conservative societies like Saudi Arabia (see Hammad and Shah, 2018). Further, more research is needed to investigate how leadership roles and practices have changed as evidence suggests that the current economic and social changes as well as reforms to educational systems in the region have impacted on these roles and practices (Alsaleh, 2019). Furthermore, there is a need for more research to understand leadership preparation/development in the region. A recent book chapter has documented the lack of research in this area and raised questions about the nature of the existing knowledge base in terms of its ability to inform leadership development programmes in Arab societies (Karami-Akkari and Hammad, 2019). It is plausible to argue that drafting a research agenda that addresses persistent EDLM issues and problems across the Gulf states is highly required if EDLM scholars in the region want their research to make a genuine difference in improving policy and practice in their societies. This is particularly important in view of the rapid changes currently taking place in the educational systems across the region.

Regarding methodological designs, Arab EDLM researchers are encouraged to reduce their heavy reliance on quantitative research and adopt alternative methods that enable them to achieve the rich descriptions needed to fully understand leadership and its related factors and challenges. Ryan and Daly (2018) specifically argue for much greater use of qualitative research methods, comparative research, and new theory building to better capture the complexity of Gulf countries like the UAE. Qualitative methods facilitate the development of "rich descriptions of practice, and can play an especially important role during the early stages of building a knowledge base" 
This is a peer-reviewed, accepted author manuscript of the following research article: Hammad, W., Samier, E. A., \& Mohammed, A. (2020). Mapping the field of educational leadership and management in the Arabian Gulf region: a systematic review of Arabic research literature. Educational Management Administration and Leadership, 1-20. https://doi.org/10.1177/1741143220937308

(Hallinger, Walker and Trung, 2015, p. 451). Methods such as focus groups designed for the Gulf context are important sources of data, particularly in a region where oral culture is still strong (Thomas, 2008). It is worth noting that some forms of qualitative research originated in the medieval Islamic classical intellectual period, notably hermeneutics, which is a dominant form of scholarship in the Islamic theological and related traditions like that of Ibn Rushd's (Giglioni, 2013), and interpretive sociological traditions established by influential scholars like Ibn Khaldun (Alatas, 2014). It could be argued that adopting culturally-appropriate methods will provide better opportunities for EDLM researchers in the region to explore sensitive issues that have remained untouched for decades.

Finally, it is hoped that this review will encourage other researchers to undertake high quality reviews of other EDLM literatures across Arab societies in the region. One limitation of this review concerns its reliance on a structural/functional approach to analysing Arabic EDLM literature. Researchers in the Arab region are encouraged to use an interpretive/critical lens in order to better understand the nature of this literature rather than just identifying its salient features. Another limitation is that the review targeted a specific set of sources within a specific period of time; there are many more EDLM research studies written in English, Arabic and French that deserve unveiling to the international community of EDLM researchers and practitioners. The review also did not consider other contributions such as postgraduate students' dissertations, conference proceedings, or books. It is envisaged that uncovering this unexplored literature will not only further our understanding of EDLM practices and challenges in this part of the Arab world, but also contribute to the shared goal of expanding the global knowledge base in the field.

\section{References}

Alatas S (2014) Applying Ibn Khaldun: The Recovery of a Lost Tradition in Sociology. Abingdon: Routledge.

Ally M and Alshahrani K (eds) (2018), Transforming Education in the Gulf Region. Abingdon: Routledge.

Alsaleh BA (2019) K-12 Education Reforms in Saudi Arabia: Implications for Change Management and Leadership Education. In: Samier EA and Elkaleh ES (eds) Teaching Educational Leadership in Muslim Countries. Singapore: Springer, pp. 171-186. 
This is a peer-reviewed, accepted author manuscript of the following research article: Hammad, W., Samier, E. A., \& Mohammed, A. (2020). Mapping the field of educational leadership and management in the Arabian Gulf region: a systematic review of Arabic research literature. Educational Management Administration and Leadership, 1-20. https://doi.org/10.1177/1741143220937308

Altbach P (2015) Academic colonialism in action: American accreditation of foreign universities.

International Higher Education (32): 5-7. Retrieved 10 March 2017, from https://ejournals.bc.edu/ojs/index.php/ihe/article/view/7373

Al-Yousef, Y. (2017) The Gulf Cooperation Council States. London: Saqi Books.

Andreotti, V. (2011) Actionable Postcolonial Theory in Education. Abingdon: Routledge.

Asuga GN Scevak J and Eacott S (2016) Educational leadership, management and administration in Africa: an analysis of contemporary literature. School Leadership \& Management 36 (4): 381-400. DOI: 10.1080/13632434.2016.1247042

Bahgat G (1999) Education in the Gulf monarchies: Retrospect and prospect. International Review of Education 45 (2):127-136.

Bailey L, Purinton T, Al-Mahdi O and Al Khalifa H (2019) Conceptualizing school leadership in the Gulf Cooperation Council (GCC) cultures: Demarcating challenges for research. Educational Management Administration \& Leadership 1741143219884682.

Bajunid I A (1996) Preliminary explorations of indigenous perspectives of educational management: The evolving Malaysian experience. Journal of Educational Administration (34):50-73.

Balcı A and Apaydın C (2009) The State of the Educational Administration Research in Turkey: The Case of the Educational Administration in Theory and Practice Journal. Educational Administration: Theory and Practice 15(59): 325-343

Belchetz D and Leithwood K (2007) Successful leadership: Does context matter and if so, how? in C. Day and K. Leithwood (Eds.), Successful principal leadership in times of change: An international perspective, Springer, Dordrecht, pp. 11-137.

Bellibaş M. Ş. and Gümüş S (2019) A systematic review of educational leadership and management research in Turkey. Journal of Educational Administration 57 (6): 731-747 
This is a peer-reviewed, accepted author manuscript of the following research article: Hammad, W., Samier, E. A., \& Mohammed, A. (2020). Mapping the field of educational leadership and management in the Arabian Gulf region: a systematic review of Arabic research literature. Educational Management Administration and Leadership, 1-20. https://doi.org/10.1177/1741143220937308

Belur J, Tompson, L, Thornton A and Simon M (2018) Interrater reliability in systematic review methodology: exploring variation in coder decision-making. Sociological methods \& research, 0049124118799372.

Blunt P and Jones ML (1997) Exploring the limits of Western leadership theory in East Asia and Africa. Personnel Review 26 (1/2):6-23.

Bridges E (1982) Research on the school administrator: The state-of-the-art 1967-1980.

Educational Administration Quarterly 18(3): 12-33.

Briner C and Campbell R F (1964) The Science of Administration. Review of Educational Research 34 (4): 485-492.

Bryman A (2016) Social Research Methods. Oxford: Oxford University Press.

Bush B (2006) Imperialism and Postcolonialism. Harlow: Pearson.

Bush T (2002) A preparation for school leadership: International perspectives. Educational Management Administration and Leadership (30): 417-429.

Bush T and Glover D (2016) School leadership and management in south africa: Findings from a systematic literature review. International Journal of Educational Management 30 (2): 211-231.

Campbell R F (1979) A Critique of the Educational Administration Quarterly. Educational Administration Quarterly 15(3): 1-19.

Castillo F A and Hallinger P (2018) Systematic review of research on educational leadership and management in Latin America, 1991-2017. Educational Management Administration \& Leadership 46(2):207-225.

Cheng K M (1995) The neglected dimension: Cultural comparison in educational administration. in K. C. Wong and K. M. Cheng (Eds.), Educational leadership and change, Hong Kong University Press, Hong Kong, pp. 87-102.

Cook W R A (2017) More vision than renaissance: Arabic as a language of science in the UAE. Language Policy 16(4): 385-406. 
This is a peer-reviewed, accepted author manuscript of the following research article: Hammad, W., Samier, E. A., \& Mohammed, A. (2020). Mapping the field of educational leadership and management in the Arabian Gulf region: a systematic review of Arabic research literature. Educational Management Administration and Leadership, 1-20. https://doi.org/10.1177/1741143220937308

Creswell, J. (2018) Research Design: Qualitative, Quantitative and Mixed Methods Approaches. Thousand Oaks: Sage.

Creswell J and Poth C (2017) Qualitative Inquiry and Research Design (International Student Edition): Choosing among Five Approaches. Thousand Oaks, CA: Sage.

Day C and Leithwood K (Eds.) (2007) Successful principal leadership in times of change: An international perspective. Dordrecht: Springer, pp. 11-137.

Denzin N and Lincoln Y (eds) (2005) The Sage Handbook of Qualitative Research. $3^{\text {rd }}$ edition. Thousand Oaks, CA: Sage.

Dimmock C and Walker A (1998) Comparative educational administration: Developing a crosscultural conceptual framework. Educational Administration Quarterly 34 (4): 558595. Doi:10. 1177/0013161X98034004006.

Dimmock C (2000) Globalisation and societal culture: Redefining schooling and school leadership in the twenty-first century. Compare: A Journal of Comparative Education (30): 1-6.

Dimmock C and Walker, A. (2005) Educational leadership: Culture and diversity. London: Sage.

El-Baz, F. (2009). Reform in Arab countries: The role of education. Journal of Education, 188(3), 41-49.

Flessa J Bramwell D Fernandez M and Weinstein J (2018) School Leadership in Latin America 2000-2016. Educational Management Administration \& Leadership 46 (2):182-206.

Giglioni G (2013) Introduction, in A. Akasoy and G. Giglioni (Eds), Renaissance Averroism and Its Aftermath: Arabic Philosophy in Early Modern Europe. Dordrecht: Springer, pp.1-34.

Glesne C (2011) Becoming Qualitative Researchers, $4^{\text {th }}$ edition. Boston: Pearson.

Hallinger, P (2020) Science mapping the knowledge base on educational leadership and management from the emerging regions of Asia, Africa and Latin America, 19652018. Educational Management Administration \& Leadership 48(2) 209-230

Hallinger P and Chen J (2015) Review of research on educational leadership and management in Asia: A comparative analysis of research topics and methods 1995-2012. Educational Management Administration \& Leadership 43 (1):5-27. 
This is a peer-reviewed, accepted author manuscript of the following research article: Hammad, W., Samier, E. A., \& Mohammed, A. (2020). Mapping the field of educational leadership and management in the Arabian Gulf region: a systematic review of Arabic research literature. Educational Management Administration and Leadership, 1-20. https://doi.org/10.1177/1741143220937308

Hallinger P and Bryant DA (2013) Mapping the terrain of research on educational leadership and management in East Asia. Journal of Educational Administration, 51(5): 618-637.

Hallinger P (1995) Culture and leadership: Developing an international perspective in educational administration. UCEA Review 36: 3-7.

Hallinger P (2013) A conceptual framework for systematic reviews of research in educational leadership and management. Journal of Educational Administration 51(2): 126-149.

Hallinger P (2018a) Surfacing a hidden literature: A systematic review of research on educational leadership and management in Africa. Educational Management Administration \& Leadership 46(3): 362-384.

Hallinger P (2011) A Review of Three Decades of Doctoral Studies Using the Principal Instructional Management Rating Scale: A Lens on Methodological Progress in Educational Leadership. Educational Administration Quarterly 47(2): 271-306.

Hallinger, P and Kovačević, J (2019) A bibliometric review of research on educational administration: Science mapping the literature, 1960 to 2018. Review of Educational Research 89(3), 335-369.

Hallinger P and Hammad W (2019) Knowledge production on educational leadership and management in Arab societies: A systematic review of research. Educational Management Administration \& Leadership 47(1):20-36.

Hallinger P, Walker A and Gian T (2015) Making Sense of Images of Fact and Fiction: A Critical Review of Research on Educational Leadership and Management in Vietnam. Journal of Educational Administration 53(4): 445-466.

Hammad Wand Hallinger P (2017) A systematic review of conceptual models and methods used in research on educational leadership and management in Arab societies. School Leadership \& Management 37(5): 434-456.

Hammad W and Shah S (2018) Dissonance Between the "International" and the Conservative "National": Challenges Facing School Leaders in International Schools in Saudi Arabia. Educational Administration Quarterly 54 (5):747-780. 
This is a peer-reviewed, accepted author manuscript of the following research article: Hammad, W., Samier, E. A., \& Mohammed, A. (2020). Mapping the field of educational leadership and management in the Arabian Gulf region: a systematic review of Arabic research literature. Educational Management Administration and Leadership, 1-20. https://doi.org/10.1177/1741143220937308

Hanafi S and Arvanitis R (2014) The marginalization of the Arab language in social science:

Structural constraints and dependency by choice. Current Sociology, 62(5): 723-742.

Hanafi S and Arvanitis R (2015) Knowledge production in the Arab world: The impossible promise. Routledge.

Ibnouf A, Dou L and Knight J (2014) The evolution of Qatar as an education hub: Moving to a knowledge-based economy. In International education hubs (pp. 43-61). Springer, Dordrecht.

Jaccard J and Jaccoby J (2020) Theory Construction and Model Building Skills. New York: Guilford Press.

Karami-Akkary R and El Sahib N (2019) A review of studies on educational administration in Arab countries (Shamaa Database 2007-2017). Idafat, (45): 67-90 (in Arabic).

Kitayama, S. and Cohen, D. (Eds.) (2007) Handbook of Cultural Psychology. New York: Guildford Press.

Leithwood K (2005) Understanding Successful Principal Leadership: Progress on a Broken Front. Journal of Educational Administration 43(6): 619-629.

Liamputtong P (2008) Doing Cross-cultural Research: Ethical and Methodological Perspectives. Dordrecht: Springer.

Miller R (2016) Desert Kingdoms to Global Powers: The Rise of the Arab Gulf. London: Yale University Press.

Noori N and Anderson P.-K (2013) Globalization, governance, and the diffusion of the American model of education: Accreditation agencies and American-style universities in the Middle East. International Journal of Politics, Culture and Society 26: 159-172.

Oplatka I and Arar K (2017) The research on educational leadership and management in the Arab world since the 1990s: A systematic review. Review of Education 5(3): 267-307.

Petttigrew M and Roberts H (2006) Systematic Reviews in the Social Sciences. MA: Blackwell, Malden. 
This is a peer-reviewed, accepted author manuscript of the following research article: Hammad, W., Samier, E. A., \& Mohammed, A. (2020). Mapping the field of educational leadership and management in the Arabian Gulf region: a systematic review of Arabic research literature. Educational Management Administration and Leadership, 1-20. https://doi.org/10.1177/1741143220937308

Riehl, C, Larson, C L, Short, P M, and Reitzug, U C (2000) Reconceptualizing research and scholarship in educational administration: Learning to know, knowing to do, doing to learn. Educational Administration Quarterly, 36(3), 391-427.

Rodriguez, E., Boatcă, M., and Costa, S. (Eds.) (2010). Decolonizing European Sociology. Farnham, UK: Ashgate.

Romani V (2009) The Politics of Higher Education in the Middle East: Problems and Prospects. Middle East Brief. Waltham, MA: Crown Center for Middle East Studies, Brandeis University.

Ryan J and Daly T (2018) Barriers to innovation and knowledge generation: The challenges of conducting business and social research in an emerging country context. Journal of Innovation \& Knowledge 4: 47-54.

Sellami A L, Sawalhi R, Romanowski, M H \& Amatullah, T (2019) Definitions of educational leadership-Arab educators' perspectives. International Journal of Leadership in Education, 1-20.

Silverman H (ed.) (2017) Research Ethics in the Arab Region. Cham: Springer.

Sunal, C. \& Mutua, K. (Eds)(2013) Influences of Educational Policy on Teaching and Learning. Charlotte, NC: Information Age.

Szeto E, Lee T T H and Hallinger P (2015) A systematic review of research on educational leadership in Hong Kong, 1995-2014. Journal of Educational Administration. 53(4): 534553.

Thomas A (2008) Focus groups in qualitative research: Culturally sensitive methodology for the Arabian Gulf? International Journal of Research \& Method in Education 31(1): 77-88.

Tian M and Huber S G (2019a) Mapping the international knowledge base of educational leadership, administration and management: a topographical perspective. Compare: A Journal of Comparative and International Education 1-20.

Tian M and Huber S (2019b) Mapping educational leadership, administration and management research 2007-2016: Thematic strands and the changing landscape. Journal of Educational Administration 58 (2): 129-150 
This is a peer-reviewed, accepted author manuscript of the following research article: Hammad, W., Samier, E. A., \& Mohammed, A. (2020). Mapping the field of educational leadership and management in the Arabian Gulf region: a systematic review of Arabic research literature. Educational Management Administration and Leadership, 1-20. https://doi.org/10.1177/1741143220937308

Walker A, R Hu and Qian H. (2012) Principal Leadership in China: An Initial Review. School Effectiveness and School Improvement 23 (4): 369-399.

Wiseman A, Alromi N and Alshumrani S (2014) Education for a Knowledge Society in Arabian Gulf Countries. Bingley: Emerald.

Young, M D and Skrla, L (Eds.) (2012) Reconsidering feminist research in educational leadership. Albany, NY: State University of New York Press.

Zahlan R (2017) The Making of the Modern Gulf States: Kuwait, Bahrain, Qatar, the United Arab Emirates and Oman. Abingdon: Routledge.

Zawacki-Richter O Kerres M Bedenlier S Bond M and Buntins K (Eds) (2020) Systematic Reviews in Educational Research. Wiesbaden: Springer. 